\title{
Evidence for perinatal and child health care guidelines in crisis settings: can Cochrane help?
}

Tari J Turner ${ }^{1,2^{*}}$, Hayley Barnes ${ }^{3}$, Jane Reid ${ }^{2}$, Marie Garrubba ${ }^{2}$

\begin{abstract}
Background: It is important that healthcare provided in crisis settings is based on the best available research evidence. We reviewed guidelines for child and perinatal health care in crisis situations to determine whether they were based on research evidence, whether Cochrane systematic reviews were available in the clinical areas addressed by these guidelines and whether summaries of these reviews were provided in Evidence Aid.

Methods: Broad internet searches were undertaken to identify relevant guidelines. Guidelines were appraised using AGREE and the clinical areas that were relevant to perinatal or child health were extracted. We searched The Cochrane Database of Systematic Reviews to identify potentially relevant reviews. For each review we determined how many trials were included, and how many were conducted in resource-limited settings.

Results: Six guidelines met selection criteria. None of the included guidelines were clearly based on research evidence. 198 Cochrane reviews were potentially relevant to the guidelines. These reviews predominantly addressed nutrient supplementation, breastfeeding, malaria, maternal hypertension, premature labour and prevention of HIV transmission. Most reviews included studies from developing settings. However for large portions of the guidelines, particularly health services delivery, there were no relevant reviews. Only 18 (9.1\%) reviews have summaries in Evidence Aid.

Conclusions: We did not identify any evidence-based guidelines for perinatal and child health care in disaster settings. We found many Cochrane reviews that could contribute to the evidence-base supporting future guidelines. However there are important issues to be addressed in terms of the relevance of the available reviews and increasing the number of reviews addressing health care delivery.
\end{abstract}

\section{Background}

Populations in crisis settings such as those resulting from natural disasters like earthquake, famine and flood, as well as man-made disasters like civil war, are at substantial risk of trauma and illness. The risks of disease and death are particularly increased for infants, children and women giving birth. Health care providers in disaster settings work with limited infrastructure, equipment, supplies and training. Given the constrained resources with which they work, health care providers in these settings cannot afford to waste time or money on ineffective or harmful treatments.

Organisations working in disaster settings are developing an awareness of the need for their practice to be based on evidence of effectiveness. Clinical practice

* Correspondence: tari.turner@med.monash.edu.au

${ }^{1}$ Monash Institute of Health Services Research, Monash University, Locked Bag 29, Clayton 3168 Australia guidelines (CPGs) and other research-based tools are increasingly being used to support effective decisionmaking, and many humanitarian aid organisations have developed their own guidelines or adapted World Health Organization (WHO) guidelines. However, it has been suggested that there is a lack of evidence-based guidelines for child and perinatal health care in crisis situations [1], and WHO guidelines have been criticised for not being appropriately evidence-based [2].

The Cochrane Collaboration supports development and dissemination of high quality, systematic reviews of health research. After the devastating tsunami affecting the Pacific Rim in December 2004, The Cochrane Collaboration aimed to contribute to the relief effort by highlighting evidence relevant to people making decisions about health care in crisis situations through a website called Evidence Aid http://www.evidenceaid.org. Evidence Aid brings together information 
from Cochrane reviews on the effects of health care interventions relevant to the aftermath of a natural disaster or other large scale health care emergency. It aims to provide quick access to reliable information about which interventions work, which don't work, and which might be harmful.

In late 2007 The Cochrane Collaboration funded an evaluation of the effectiveness of Evidence Aid, which included an exploration of the ways in which Evidence Aid could contribute to meeting the health information needs of humanitarian organisations. In parallel with the evaluation of Evidence Aid, we reviewed existing guidelines for child and perinatal health care in crisis situations to determine what areas of clinical practice were addressed by these guidelines, and whether summaries of Cochrane systematic reviews relevant to these clinical areas were provided in Evidence Aid.

In this study we had several aims;

- to identify existing guidelines for perinatal and child health in crisis settings and examine whether these guidelines were explicitly based on research evidence,

- to determine whether relevant Cochrane systematic reviews were available in the clinical areas addressed by these guidelines and to ascertain whether summaries of these reviews were provided in Evidence Aid.

\section{Methods}

\section{Identifying Existing Guidelines Search Strategy}

We undertook a broad search to identify existing guidelines for child and perinatal health care in crisis situations. We searched guideline websites, websites of humanitarian organisations and aid networks, and the internet using Google, with search terms including (emergency OR disaster OR crisis) AND (guideline OR evidence OR handbook OR manual).

Guideline websites included:

- US National Guidelines Clearinghouse http://www. guidelines.gov

- Guidelines International Network http://www.g-i-n. net,

- The Scottish Intercollegiate Guidelines Network http://www.sign.ac.uk

- The National Institute for Health and Clinical Excellence, http://www.nice.org.uk,

- The New Zealand Guidelines Group http://www. nzgg.org.nz

- The National Health and Medical Research Council http://www.nhmrc.gov.au
Humanitarian organisations and aid networks websites included:

- The World Health Organization http://www.who. int

- United Nations Office for the Coordination of Humanitarian Affairs http://ochaonline.un.org/

- The International Committee of the Red Cross http://www.icrc.org,

- Medecins Sans Frontieres http://www.msf.org,

- CARE http://www.care.org

- SPHERE http://www.sphereproject.org

- ReliefWeb http://www.reliefweb.int.

\section{Selection Criteria}

To be included guidelines had to be explicitly developed to provide guidance on health care interventions for child and perinatal conditions in crisis situations. Guidelines which provided policy, training or other guidance, but did not provide recommendations to guide decisions on provision of particular health care interventions were excluded as were guidelines that were not specifically developed to be implemented in crisis or emergency settings. We only included guidelines published in English. Selection criteria were applied independently by four reviewers, and disagreements resolved through discussion.

\section{Quality Appraisal}

As recommended by the AGREE Collaboration, included guidelines were appraised by four reviewers using the AGREE criteria, which are the standard for appraising the quality of evidence-based guidelines [3]. Guidelines were first assessed to determine whether they were based on systematic searches, and whether guideline recommendations were clearly linked to research evidence (AGREE criteria 8 \& 12). Guidelines that did not meet these basic criteria of evidence-based guidelines were not further appraised. Guidelines that met these initial criteria were then fully appraised using the AGREE instrument.

\section{Data Extraction}

Two reviewers created a list of the clinical areas (disease/condition, symptom or intervention) addressed by each included guideline that were relevant to perinatal or child health.

\section{Identifying Relevant Cochrane Reviews Search Strategy}

For each clinical area extracted from the guidelines, we searched The Cochrane Database of Systematic Reviews http://www.thecochranelibrary.com Issue 2, 2008; using simple text word and MeSH searches of the title, 
abstract and keywords, to identify potentially relevant reviews. We searched only for Cochrane systematic reviews as this was part of a project exploring how Evidence Aid, which was developed by the Cochrane Collaboration and provides summaries of Cochrane systematic reviews, could contribute to meeting the health information needs of humanitarian organisations.

\section{Data Extraction}

For each potentially relevant review, one reviewer read the 'Description of Studies' section, 'Characteristics of Included Studies' table and 'References' section to determine how many trials were included in the review, and how many of these trials were conducted in a developing setting.

\section{Results}

Fourteen potentially relevant guidelines were identified and six guidelines met selection criteria [4-9] (Tables 1 and 2). Of these six guidelines, three focused on feeding and nutrition for infants, children and/or pregnant and lactating women in emergencies $[4,7,8]$, one addressed provision of antenatal care in crisis settings[5] and two covered all aspects of care for children in emergencies $[6,9]$.

However, none of the included guidelines were explicitly based on systematic searches of research literature, or had recommendations that were clearly linked to research evidence (AGREE criteria 8 \& 12). As a result none of the guidelines were assessed using the full AGREE instrument. One guideline did not include any references, one included references in a "Further reading" section and three included references, but these were not directly linked to the recommendations of the guideline. None of the guidelines included any Cochrane or other systematic reviews as references. None of the included guidelines described the methods by which they were developed.

Table 3 contains the reference numbers of the potentially relevant Cochrane systematic reviews and protocols for each guideline; the titles of these reviews and protocols are matched to the relevant guideline sections in Additional File 1 Table S1.

The "Infant and Young Child Feeding in Emergencies" guideline [4] produced in 2007 by the Infant and Young Child Feeding in Emergencies (IFE) Core Group provides guidance on how to feed infants and children in crisis settings. There were 14 Cochrane systematic reviews and six protocols for reviews that were potentially relevant to this guideline, predominantly addressing nutrient supplementation, support for breastfeeding and prevention of mother to child HIV transmission. All except two of the reviews include some studies from

Table 1 Included guidelines

\begin{tabular}{lll}
\hline Title & Date & Developer \\
\hline Manual for the health care of children in humanitarian emergencies [9] & 2008 & WHO \\
\hline Infant and Young Child Feeding in Emergencies [4] & 2007 & IFE Core Group \\
\hline Community-based Therapeutic Care (CTC) A Field Manual [7] & 2006 & Valid International \\
\hline Antenatal Guidelines For Primary Health Care In Crisis Conditions [5] & 2005 & ICRC \\
\hline Guiding principles for feeding infants and young children during emergencies [8] & 2004 & WHO \\
\hline Emergency Field Handbook A Guide For UNICEF Staff [6] & Unclear & UNICEF \\
\hline
\end{tabular}

Table 2 Excluded guidelines

\begin{tabular}{|c|c|c|c|}
\hline Title & Date & Developer & Reason for exclusion \\
\hline $\begin{array}{l}\text { Clinical Guidelines: Diagnosis and Treatment Manual for curative } \\
\text { programs in hospitals and dispensaries [10] }\end{array}$ & 2007 & MSF & Not crisis setting \\
\hline $\begin{array}{l}\text { Obstetrics in Remote Settings: Practical guide for non-specialized } \\
\text { health professionals [11] }\end{array}$ & 2007 & MSF & Not crisis setting \\
\hline $\begin{array}{l}\text { Pregnancy, Childbirth, Postpartum and Newborn Care: A guide for } \\
\text { essential practice [12] }\end{array}$ & 2006 & $\mathrm{WHO}$ & Not crisis setting \\
\hline Diarrhoea Treatment Guidelines Clinic-Based Healthcare Workers [13] & 2005 & MOST & Not crisis setting \\
\hline Care of the Newborn Reference Manual [14] & 2004 & $\begin{array}{l}\text { Save the Children } \\
\text { Federation }\end{array}$ & Not crisis setting \\
\hline Food and Nutrition Needs in Emergencies [15] & 2002 & $\begin{array}{l}\text { UNHCR, UNICEF, } \\
\text { WFP and WHO }\end{array}$ & $\begin{array}{l}\text { Scope covered by more recent publication } \\
\text { from the same organisations }\end{array}$ \\
\hline The management of nutrition in major emergencies [16] & 2000 & $\mathrm{WHO}$ & $\begin{array}{l}\text { Scope covered by more recent publication } \\
\text { from the same organisations }\end{array}$ \\
\hline Acute Respiratory Infections In Children [17] & Unclear & $\mathrm{WHO}$ & Not crisis setting \\
\hline
\end{tabular}


Table 3 References for Cochrane systematic reviews and protocols potentially relevant to each of the guidelines

\begin{tabular}{|c|c|c|c|}
\hline Guideline & Cochrane systematic reviews & Protocols for reviews & $\begin{array}{l}\text { Reviews with no included studies from } \\
\text { developing settings }\end{array}$ \\
\hline $\begin{array}{l}\text { Infant and Young } \\
\text { Child Feeding in } \\
\text { Emergencies [4] }\end{array}$ & {$[18-31]$} & {$[32-37]$} & {$[21,24]$} \\
\hline $\begin{array}{l}\text { Community-based } \\
\text { Therapeutic Care } \\
\text { (CTC) A Field } \\
\text { Manual [7] }\end{array}$ & {$[20,23,26,38-69]$} & {$[32,34,35,37,70-77]$} & $\begin{array}{l}66] \\
\text { Unclear: [60-62] }\end{array}$ \\
\hline $\begin{array}{l}\text { Guiding principles } \\
\text { for feeding infants } \\
\text { and young } \\
\text { children during } \\
\text { emergencies [8] }\end{array}$ & $\begin{array}{l}{[18,19,22,23,25-28,30,31,44,48,49} \\
53,58,60-62,64-69,78-86]\end{array}$ & {$[32,34,35,37,71,73,75,87-89]$} & $\begin{array}{l}\text { [66,79], } \\
\text { Unclear: }[60-62,81] .\end{array}$ \\
\hline $\begin{array}{l}\text { Antenatal } \\
\text { Guidelines For } \\
\text { Primary Health } \\
\text { Care In Crisis } \\
\text { Conditions [5] }\end{array}$ & {$[25,27,28,30,31,48,60,61,64,90-194]$} & {$[195-206]$} & $\begin{array}{l}{[91,92,95,99,101,107,108,116,117,121,125,127,} \\
128,130,134,135,138,141,147,151,162,163,167, \\
171,172,176,177,179,180,182,184,186,192,194] \\
\text { Unclear: } \\
{[60,61,90,96,98,100,106,109-111,114,119,129,131,} \\
132,140,146,149,150,157,158,166,173,175,188,193]\end{array}$ \\
\hline $\begin{array}{l}\text { Emergency Field } \\
\text { Handbook: A } \\
\text { Guide For UNICEF } \\
\text { Staff [6] }\end{array}$ & $\begin{array}{l}{[18,19,22,26,27,39-43,45-48,50-54,56-59,} \\
61-63,65-69,78,83-85,105,191,207-231]\end{array}$ & {$[35,36,73-75,77,87,88,232-244]$} & $\begin{array}{l}\text { [66,207,213,222-224,230], } \\
\text { Unclear: }[61,62] .\end{array}$ \\
\hline $\begin{array}{l}\text { Manual for the } \\
\text { health care of } \\
\text { children in } \\
\text { humanitarian } \\
\text { emergencies[9] }\end{array}$ & $\begin{array}{l}{[18,22,23,26,28,30,31,39-43,45-47,53,54,56,57,} \\
59,62,78,83-86,105,207,208,210,215,216,218, \\
222,223,225,226,228-230,245-257]\end{array}$ & {$[36,37,233,235,237,238,241,258]$} & {$[207,223,230,250]$ Unclear: $[62,248,255]$} \\
\hline
\end{tabular}

developing settings. However for large portions of the guideline, particularly those focusing on procurement and distribution of infant formula, and coordinating, monitoring and assessing the success of feeding programs, there were no relevant reviews in The Cochrane Library.

For the Valid International Guideline "Communitybased Therapeutic Care (CTC) A Field Manual" [7], which focuses on nutritional support for children, pregnant and lactating women, there were 35 potentially relevant Cochrane systematic reviews and 12 protocols. All of the reviews except one appeared to include studies from developing settings, however in three reviews the study settings were unclear. The potentially relevant reviews focused primarily on the effectiveness of supplementation with particular nutrients and choice of treatment for malaria. There were no relevant reviews addressing assessing malnutrition, planning, establishing, monitoring or evaluating a nutrition supplement program, which makes up the majority of the field manual.

There were 34 Cochrane reviews and 10 protocols potentially relevant to the World Health Organization's "Guiding principles for feeding infants and young children during emergencies" [8] guideline. As with the previous two guidelines, these reviews were primarily related to nutritional supplementation for infants and their mothers, as well as support for establishment and maintenance of breastfeeding. All but two trials appeared to include studies from developing settings, however in four reviews the study settings were unclear.

For the guideline addressing antenatal care "Antenatal Guidelines For Primary Health Care In Crisis Conditions" [5] produced by the International Committee of the Red Cross, there were 114 Cochrane systematic reviews and 12 protocols that were potentially relevant. The majority of these reviews addressed clinical management of hypertension, pre-eclampsia and eclampsia; or management of premature labour. For 34 of these reviews there were no included studies from developing settings, and in an additional 25 it was unclear how many studies were conducted in developing settings. The proportion of potentially relevant reviews where the included studies were all conducted in developed settings, or the setting was unclear was much larger for this guidelines than the others.

The "Emergency Field Handbook: A Guide For UNICEF Staff" [6] produced by UNICEF covers provision of protection and assistance to children and women in emergencies including: assessment, co-ordination, program delivery, security, communication, logistics and human resources. Sixty-two Cochrane systematic reviews and 21 protocols were potentially relevant to the content of this handbook; however, almost all of 
these were relevant to the section 'Health and Nutrition' which constitutes only approximately 20 percent of the content of the handbook. Very few Cochrane reviews were relevant to the rest of the content. There were no studies from developing settings in seven of the potentially relevant Cochrane reviews, and in another two reviews the setting of the included studies was unclear.

The WHO "Manual for the health care of children in humanitarian emergencies"[9] aims to provide guidance on the care of children in the acute and chronic phases of an emergency, where there are no inpatient hospital facilities. The content included diarrhoea and dehydration, cough or difficulty breathing, fever, malnutrition, anaemia, injuries, burns, poisoning, immunization and other public health measures, prevention of HIV Infection in children, and mental health and psychosocial support. There were 56 Cochrane reviews and eight protocols relevant to the content of this guideline, addressing much of the guideline content. However few reviews or protocols were found for topics on injury management, malnutrition, burns, or emergency assessment and triage. Research from developing settings was included in all but seven of the potentially relevant Cochrane reviews.

Of the total of 198 Cochrane systematic reviews that were identified as being potentially relevant to the content of the included guidelines, 18 (9.1\%) have summaries in Evidence Aid. Links to the full text of the reviews are provided for a further twelve (6.1\%).

\section{Discussion}

Echoing what has been found previously [1], we were unable to identify any explicitly evidence-based guidelines to support decision-making around perinatal and child health care in crisis settings. The limited resources available and the enormous proportion of the burden of illness and death resulting from disasters borne by this portion of the population, mean that ensuring care delivery is evidence-based is vitally important for this setting.

It is possible to imagine a world where guidelines in all areas of clinical practice would provide recommendations based on systematic reviews of the best available evidence, integrated with clinical expertise and patient preferences. Cochrane reviews would be available to answer every clinical question, and after searching the Cochrane Database of Systematic Reviews, guidelines would be written, and we could be confident that the recommended care was based on a solid foundation of research evidence. However this ideal is unlikely to ever be achieved. Existing evidence-based guideline development methods are time-consuming and resource-intensive and often produce guidelines which are only applicable in a narrow range of contexts. Guideline developers do not always search for the best available research evidence, or do not document the methods used so that the evidence base on which the guidelines are developed cannot be established. Cochrane systematic reviews are not available to cover every possible clinical question, and many do not address issues of applicability and generalisability. In many areas primary research is not available, or is not directly relevant to the guideline being developed. These problems are exacerbated by the fact that it is very difficult to carry out primary research in crisis settings, and that most health research is carried out in well resourced settings, to address the health concerns of well resourced populations. As a result there is less primary research available relevant to crisis settings and potentially fewer relevant systematic reviews.

In spite of the barriers to the production of systematic reviews relevant to crisis settings, our results demonstrate that there are Cochrane reviews available which have the potential to support health care decision-making in perinatal and child health in crisis settings. A large number of potentially relevant reviews were identified. The great majority of the identified reviews include some studies that were undertaken in resource-poor settings, however very few, if any, were conducted in crisis settings. The contribution Cochrane reviews can make in the crisis setting is further limited in a number of important ways.

The Cochrane Database of Systematic Reviews includes few reviews on health system issues, focusing more on reviews of clinical interventions. While we only included guidelines that addressed at least one area of clinical practice, several of the included guidelines had substantial sections addressing establishing, prioritising or evaluating healthcare programs, and there is a clear need for evidence to support decision-making in these areas. The Cochrane Collaboration's contribution to synthesising research about health care delivery systems is currently limited, though may increase through the work of the Effective Practice and Organisation of Care group within the Collaboration. The critical need for this kind of evidence was also identified in our interviews with potential users of Evidence Aid as part of the broader Evidence Aid evaluation.

The large number of protocols for systematic reviews that are potentially relevant to the included guidelines suggests that the Cochrane Collaboration's contribution to the evidence-base of guidelines for perinatal and child health in crisis settings is likely to grow into the future. However the majority of these protocols address areas similar to those addressed in existing reviews, and the reviews arising from these protocols will not address the gap in evidence relating to health care delivery systems. This gap might be addressed by 
establishing processes to prioritise reviews in these areas of identified need and substantial morbidity and mortality.

Also, while The Cochrane Collaboration is developing methods for reviews of diagnostic studies, the Cochrane Database of Systematic Reviews does not currently include reviews of diagnosis, but only therapy. As a result, Cochrane reviews cannot inform decisions about diagnostic approaches, limiting their potential contribution to clinical practice guidelines.

Several issues impact on the potential relevance of the Cochrane reviews identified. One is the context in which most of the primary studies included in systematic reviews are conducted. The majority of these primary studies are undertaken in stable, developed countries, rather than unstable, resource-poor settings, where large scale emergencies are most common, and have the largest impact on increasing morbidity and mortality. This was particularly clear in the Cochrane reviews evaluating the impact of various forms of dietary supplementation. In many of these reviews the primary studies were not carried out in populations, like those seen in crisis situations, where dietary deficiencies are common. The effects of the supplements evaluated are likely to be very different in these settings, compared to those in which the studies were largely carried out. This highlights the importance of documenting the context of primary research studies included in systematic reviews.

When evidence-based guidelines make recommendations for practice, they often use evidence which was generated in contexts that are different from the one in which the guideline will be applied. In some situations evidence is available that was generated in a very similar context. However where this type of immediately relevant evidence is not available, guideline developers rely on other evidence, and draw conclusions about whether and/or how it is likely to apply in their context. The degree to which the context impacts on the applicability of the research varies with the nature of the clinical practice.

It is difficult to tightly define terms like 'crisis', 'disaster' and 'emergency'. We chose a very broad definition "crisis settings such as those resulting from natural disasters like earthquake, famine and flood, as well as manmade disasters like civil war", designed to be inclusive, but to differentiate from what might be considered 'stable' situations in resource-poor settings. However the threshold between crisis and non-crisis is essentially arbitrary and there will always be grey areas. There are many examples where 'normal' conditions in resourcepoor settings have deteriorated so that they could reasonably be described as crisis situations and also where crisis situations have become so chronic and entrenched that they are essentially 'stable'.
In developing guidelines for crisis situations, there will be times when it is appropriate to base recommendations on evidence established in stable situations and other times when the evidence must be generated in crisis settings to be relevant to the practice in question. Similarly some guidelines developed for use in stable situations may be relevant and appropriate for use in crisis situations. The nature of crisis situations varies widely. Crises arise from many different causes, and take place in contexts with widely varying health infrastructure, staff availability, geography and underlying health problems, etc. All of these factors will affect the relevance of research and guidelines generated in other settings.

A second factor impacting on the potential relevance is the availability of the interventions evaluated in the Cochrane reviews. While we attempted to include only those reviews addressing interventions which were potentially feasible in crisis settings (guided by the interventions recommended by the guidelines themselves); in the aftermath of emergencies, clinicians are often working with a very limited toolkit of equipment and drugs, and these may vary from one situation to another. As a result, some of the reviews which we believe might be potentially relevant may recommend interventions which are not affordable or practical in some crisis settings. However, the large number of potentially relevant Cochrane reviews identified suggests that, even taking these factors into account, Cochrane reviews can still make a substantial contribution to supporting health care decision-making in these contexts.

A relatively small percentage of the Cochrane reviews identified as being potentially relevant to informing guidelines for perinatal and child health in crisis settings currently have summaries in Evidence Aid. So the results of these reviews are only available to those who have access to the full text of The Cochrane Library. As a result The Cochrane Collaboration is missing an opportunity to provide evidence to support humanitarian organisations developing guidelines in these areas. This gap may result from a lack of awareness that the results of these reviews would potentially be valuable in these settings, or, perhaps more likely, from time and resource limitations on the production of the Evidence Aid summaries, a process that requires a substantial investment of time and intellect.

This review is limited by our focus on guidelines in the field of perinatal and child health, which may not be representative of the state of guidelines in other areas of emergency health care. However infants, children and pregnant women are particularly at risk in the aftermath of emergencies, and so we feel this focus is reasonable, if largely pragmatic. The review was also limited to those guidelines that were available in English on the internet. High quality evidence-based guidelines relevant to this area may have been developed but not made 
publicly available. We chose to focus on the health issues surrounding crisis situations, however we acknowledge that these situations also involve environmental, engineering and social problems. Our focus was on health issues as this our area of expertise and this is also the area in which the methods for developing clinical practice guidelines have been established. The study is also limited to assessing the reviews that are available at the current time, which may be different from those available at the time the guidelines were developed, which was not always clear from the guidelines. However the included guidelines were all developed relatively recently, and this study highlights that there is evidence relevant to this area of clinical practice that could be used as the basis of future guideline development.

\section{Conclusion}

We were unable to identify any explicitly evidence-based guidelines to support decision-making around perinatal and child health care in disaster settings. We found that there are many Cochrane reviews available that have the potential to contribute to the evidence-base supporting guidelines for perinatal and child health in disaster settings in the future, and that most of these reviews include some studies conducted in developing settings. However there are also important issues to be addressed in terms of the relevance of the available reviews and increasing the number of reviews addressing questions of health care delivery.

Additional file 1: Table S1. Details of potentially relevant Cochrane systematic reviews and protocols for each guideline

\begin{abstract}
Acknowledgements
Our thanks to Sally Green, Claire Harris and Katrina Williams for comments during the development of this research and drafts of this article. Funding

This study was funded through an Australian Postgraduate Award provided by the Australian Federal Government. Internal support was provided by the Centre for Clinical Effectiveness, Southern Health and Monash Institute of Health Services Research, Monash University.

\section{Author details}

${ }^{1}$ Monash Institute of Health Services Research, Monash University, Locked Bag 29, Clayton 3168 Australia. ${ }^{2}$ Centre for Clinical Effectiveness, Southern Health, Locked Bag 29, Clayton 3168 Australia. ${ }^{3}$ previously of the Australasian Cochrane Centre, Monash University, Locked Bag 29, Clayton 3168 Australia.
\end{abstract}

\section{Authors' contributions}

$\pi$ conceived of this project and developed the methodology and data extraction approach, which $H B, J R$ and MG refined. $T$ and $M G$ undertook the searches. $\Pi$ T, HB, JR and MG applied the AGREE criteria. TT undertook the data extraction with assistance from $\mathrm{HB}$ and JR. TT prepared the first draft of this article which $H B, J R, M G$ and $\Pi$ then revised. $T$ had full access to all the data in the study and had final responsibility for the decision to submit for publication. All authors read and approved the final manuscript

\section{Competing interests}

TT undertook a PhD supervised by the Director of the Australasian Cochrane Centre (ACC) which included an evaluation of Evidence Aid, funded through a grant from The Cochrane Collaboration Steering Group Discretionary Fund. HB was previously employed by the ACC. JR and MG both work on projects, unrelated to this project, in which ACC is a collaborator.

Received: 3 June 2009 Accepted: 29 March 2010

Published: 29 March 2010

\section{References}

1. Moss WJ, Ramakrishnan M, Storms D, Henderson Siegle A, Weiss WM, Lejnev I, Muhe L: Child health in complex emergencies. Bull World Health Organ 2006, 84:58-64.

2. Oxman A, Lavis J, Fretheim A: Use of evidence in WHO recommendations. The Lancet 2007, 369:1883-1889.

3. Development and validation of an international appraisal instrument for assessing the quality of clinical practice guidelines: the AGREE project. Qual Saf Health Care 2003, 12:18-23.

4. Infant and Young Child Feeding in Emergencies (IFE) Core Group: Infant and Young Child Feeding in Emergencies: Operational Guidance for Emergency Relief Staff and Programme Managers. IFE Core Group (UNICEF, WHO, UNHCR, WFP, IBFAN-GIFA, CARE USA, Fondation Terre des hommes and the Emergency Nutrition Network (ENN)) 2007.

5. Otero GC: Antenatal Guidelines For Primary Health Care In Crisis Conditions. Geneva, International Committee of the Red Cross 2005

6. UNICEF: Emergency Field Handbook. A Guide For UNICEF Staff. UNICEF 2005.

7. Valid International: Community-based Therapeutic Care (CTC): A Field Manual. CTC Research and Development programme, a collaboration between Valid International and Concern Worldwide 2006.

8. World Health Organization: Guiding principles for feeding infants and young children during emergencies. Geneva, World Health Organization 2004.

9. Muhe L, Gayer M, Moss W, (Eds): Manual for the health care of children in humanitarian emergencies. Geneva, World Health Organization 2008.

10. Medecins Sans Frontieres: Clinical Guidelines: Diagnosis and Treatment Manual for curative programs in hospitals and dispensaries. Medecins Sans Frontieres 2007.

11. Medecins Sans Frontieres: Obstetrics in Remote Settings: Practical guide for non-specialized health professionals. Medecins Sans Frontieres 2007.

12. World Health Organization: Pregnancy, Childbirth, Postpartum and Newborn Care: A guide for essential practice. Geneva, World Health Organization 2006.

13. MOST (The USAID Micronutrient Program): Diarrhoea Treatment Guidelines for Clinic-Based Healthcare Workers. MOST 2005.

14. Federation StC: Care of the Newborn Reference Manual. Washington DC, Save the Children 2004.

15. UNHCR UNICEF WFP and WHO: Food and Nutrition Needs in Emergencies. UNHCR, UNICEF, WFP and WHO 2002.

16. World Health Organization: The management of nutrition in major emergencies. Geneva, World Health Organization 2000.

17. World Health Organization: Acute Respiratory Infections In Children. Geneva, World Health Organization.

18. Britton C, McCormick FM, Renfrew MJ, Wade A, King SE: Support for breastfeeding mothers. Cochrane Database Syst Rev 2007, CD001141.

19. Flint A, New K, Davies MW: Cup feeding versus other forms of supplemental enteral feeding for newborn infants unable to fully breastfeed. Cochrane Database Syst Rev 2007, CD005092.

20. Haider BA, Bhutta ZA: Multiple-micronutrient supplementation for women during pregnancy. Cochrane Database Syst Rev 2006, CD004905.

21. Henderson G, Anthony MY, McGuire W: Formula milk versus maternal breast milk for feeding preterm or low birth weight infants. Cochrane Database Syst Rev 2007, CD002972.

22. Kramer MS, Kakuma R: Optimal duration of exclusive breastfeeding. Cochrane Database Syst Rev 2002, CD003517.

23. Logan S, Martins S, Gilbert R: Iron therapy for improving psychomotor development and cognitive function in children under the age of three with iron deficiency anaemia. Cochrane Database Syst Rev 2001, CD001444.

24. Quigley MA, Henderson G, Anthony MY, McGuire W: Formula milk versus donor breast milk for feeding preterm or low birth weight infants. Cochrane Database Syst Rev 2007, CD002971. 
25. Read JS, Newell MK: Efficacy and safety of cesarean delivery for prevention of mother-to-child transmission of HIV-1. Cochrane Database Syst Rev 2005, CD005479.

26. Sguassero Y, de Onis M, Carroli G: Community-based supplementary feeding for promoting the growth of young children in developing countries. Cochrane Database Syst Rev 2005, CD005039.

27. Sibley LM, Sipe TA, Brown CM, Diallo MM, McNatt K, Habarta N: Traditional birth attendant training for improving health behaviours and pregnancy outcomes. Cochrane Database Syst Rev 2007, CD005460.

28. Volmink J, Siegfried NL, Merwe van der L, Brocklehurst P: Antiretrovirals for reducing the risk of mother-to-child transmission of HIV infection. Cochrane Database Syst Rev 2007, CD003510.

29. Weller SC, Davis-Beaty K: Condom effectiveness in reducing heterosexual HIV transmission. Cochrane Database Syst Rev 2002, CD003255.

30. Wiysonge CS, Shey MS, Shang JD, Sterne JA, Brocklehurst P: Vaginal disinfection for preventing mother-to-child transmission of HIV infection Cochrane Database Syst Rev 2005, CD003651.

31. Wiysonge CS, Shey MS, Sterne JA, Brocklehurst P: Vitamin A supplementation for reducing the risk of mother-to-child transmission of HIV infection. Cochrane Database Syst Rev 2005, CD003648.

32. Adetifa IMO, Okomo U: Iron supplementation for reducing morbidity and mortality in children with HIV. Cochrane Database of Systematic Reviews: Protocols 2007, CD006736.

33. Fraser A, Bilenko N, Paul M, Leibovici L, Fraser D: Supplementation with two or more micronutrients versus single micronutrient supplementation or placebo in young children. Cochrane Database of Systematic Reviews: Protocols 2006, CD005977.

34. Martins S, Logan S, Gilbert R: Iron supplementation for improving psychomotor development and cognitive function in infants under the age of one. Cochrane Database of Systematic Reviews: Protocols 2001, CD003016.

35. Ojukwu JU, Okebe JU: Routine iron supplementation for preventing or treating iron-deficiency anaemia in children in malaria-endemic areas. Cochrane Database of Systematic Reviews: Protocols 2007, CD006589.

36. Tholandi M, Wilkinson D, Dabis F, Kennedy G, Madi B, Leroy V: Interventions to decrease the risk of mother-to-child transmission of HIV-1 through breast milk. Cochrane Database of Systematic Reviews: Protocols 2003, CD004247.

37. Xiaoxi $Z, W u$ T: Iron supplementation for iron deficiency anemia in children. Cochrane Database of Systematic Reviews: Protocols 2007, CD006465

38. Mabey D, Fraser-Hurt N, Powell C: Antibiotics for trachoma. Cochrane Database Syst Rev 2005, CD001860.

39. Omari AA, Gamble C, Garner P: Artemether-lumefantrine (four-dose regimen) for treating uncomplicated falciparum malaria. Cochrane Database Syst Rev 2006, CD005965.

40. Omari AA, Gamble C, Garner P: Artemether-lumefantrine (six-dose regimen) for treating uncomplicated falciparum malaria. Cochrane Database Syst Rev 2005, CD005564.

41. Bukirwa $H$, Orton L: Artesunate plus mefloquine versus mefloquine for treating uncomplicated malaria. Cochrane Database Syst Rev 2005, CD004531.

42. Jones KL, Donegan S, Lalloo DG: Artesunate versus quinine for treating severe malaria. Cochrane Database Syst Rev 2007, CD005967.

43. Osei-Akoto A, Orton L, Owusu-Ofori SP: Atovaquone-proguanil for treating uncomplicated malaria. Cochrane Database Syst Rev 2005, CD004529.

44. Winzenberg TM, Shaw K, Fryer J, Jones G: Calcium supplementation for improving bone mineral density in children. Cochrane Database Syst Rev 2006, CD005119.

45. Mclntosh HM, Jones $\mathrm{KL}$ : Chloroquine or amodiaquine combined with sulfadoxine-pyrimethamine for treating uncomplicated malaria. Cochrane Database Syst Rev 2005, CD000386.

46. Bukirwa H, Garner P, Critchley J: Chlorproguanil-dapsone for treating uncomplicated malaria. Cochrane Database Syst Rev 2004, CD004387.

47. Taylor-Robinson DC, Jones AP, Garner P: Deworming drugs for treating soil-transmitted intestinal worms in children: effects on growth and school performance. Cochrane Database Syst Rev 2007, CD000371.

48. Pena-Rosas JP, Viteri FE: Effects of routine oral iron supplementation with or without folic acid for women during pregnancy. Cochrane Database Syst Rev 2006, 3:CD004736.
49. Kramer MS, Kakuma R: Energy and protein intake in pregnancy. Cochrane Database Syst Rev 2003, CD000032.

50. Rabiu M, Alhassan $\mathrm{M}$, Ejere $\mathrm{H}$ : Environmental sanitary interventions for preventing active trachoma. Cochrane Database Syst Rev 2007, CD004003.

51. Ejere $\mathrm{H}$, Alhassan MB, Rabiu M: Face washing promotion for preventing active trachoma. Cochrane Database Syst Rev 2004, CD003659.

52. Panpanich R, Garner P: Growth monitoring in children. Cochrane Database Syst Rev 2000, CD001443.

53. Ejemot Rl, Ehiri JE, Meremikwu MM, Critchley JA: Hand washing for preventing diarrhoea. Cochrane Database Syst Rev 2008, CD004265.

54. Lesi $A$, Meremikwu M: High first dose quinine regimen for treating severe malaria. Cochrane Database Syst Rev 2004, CD003341.

55. Strong M, Johnstone PW: Interventions for treating scabies. Cochrane Database Syst Rev 2007, CD000320.

56. Afolabi BB, Okoromah CN: Intramuscular arteether for treating severe malaria. Cochrane Database Syst Rev 2004, CD004391.

57. Eisenhut M, Omari AA: Intrarectal quinine for treating Plasmodium falciparum malaria. Cochrane Database Syst Rev 2005, CD004009.

58. Angermayr $L$, Clar C: lodine supplementation for preventing iodine deficiency disorders in children. Cochrane Database Syst Rev 2004, CD003819.

59. Bukirwa $H_{\text {, }}$ Critchley J: Sulfadoxine-pyrimethamine plus artesunate versus sulfadoxine-pyrimethamine plus amodiaquine for treating uncomplicated malaria. Cochrane Database Syst Rev 2006, CD004966.

60. Dodd J, Dare MR, Middleton P: Treatment for women with postpartum iron deficiency anaemia. Cochrane Database Syst Rev 2004, CD004222.

61. Reveiz L, Gyte GM, Cuervo LG: Treatments for iron-deficiency anaemia in pregnancy. Cochrane Database Syst Rev 2007, CD003094.

62. Demicheli $V$, Jefferson $T$, Rivetti A, Price D: Vaccines for measles, mumps and rubella in children. Cochrane Database Syst Rev 2005, CD004407.

63. Chen H, Zhuo Q, Yuan W, Wang J, Wu T: Vitamin A for preventing acute lower respiratory tract infections in children up to seven years of age. Cochrane Database Syst Rev 2008, CD006090.

64. Van DE, Kulier R, Gulmezoglu AM, Villar J: Vitamin A supplementation during pregnancy. Cochrane Database Syst Rev 2002, CD001996.

65. Rumbold A, Crowther CA: Vitamin C supplementation in pregnancy. Cochrane Database Syst Rev 2005, CD004072.

66. Mahomed K, Gulmezoglu AM: Vitamin D supplementation in pregnancy. Cochrane Database Syst Rev 2000, CD000228.

67. Rumbold A, Crowther CA: Vitamin E supplementation in pregnancy. Cochrane Database Syst Rev 2005, CD004069.

68. Mahomed K, Bhutta Z, Middleton P: Zinc supplementation for improving pregnancy and infant outcome. Cochrane Database Syst Rev 2007 CD000230

69. Wu T, Liu GJ, Li P, Clar C: lodised salt for preventing iodine deficiency disorders. Cochrane Database Syst Rev 2002, CD003204

70. Gray PH, Nourse CB, Peeler A: Antifungal agents for the treatment of mucocutaneous candidiasis in neonates and children. Cochrane Database of Systematic Reviews: Protocols 2004, CD004867.

71. Buppasiri P, Lumbiganon P, Thinkhamrop J, Ngamjarus C: Calcium supplementation (other than for preventing or treating hypertension) for improving pregnancy and infant outcomes. Cochrane Database of Systematic Reviews: Protocols 2008, CD007079.

72. Haider BA, Bhutta ZA: Effects of interventions for helminthic infections in pregnancy. Cochrane Database of Systematic Reviews: Protocols 2005, CD005547.

73. Haider BA, Humayun Q, Bhutta ZA: Folate supplementation in pregnancy. Cochrane Database of Systematic Reviews: Protocols 2008, CD006896.

74. Haider Batool A, Irfan Furqan B, Bhutta Zulfiqar A: Neonatal vitamin A supplementation for the prevention of mortality and morbidity in term neonates in developing countries. Cochrane Database of Systematic Reviews: Protocols 2008, CD006980.

75. Oliveira JM, Bergamaschi DP, East CE, Pai M: Vitamin A supplementation for breastfeeding mothers. Cochrane Database of Systematic Reviews: Protocols 2006, CD005944.

76. Winzenberg TM, Powell S, Shaw KA, Jones G: Vitamin D supplementation for improving bone mineral density in children. Vitamin $D$ supplementation for improving bone mineral density in children Cochrane Database of Systematic Reviews: Protocols 2008 John Wiley \& Sons, Ltd ChichesterWinzenberg TM, Powell S, Shaw KA, Jones G 2008, 1: CD006944. 
77. Haider BA, Saeed MA, Bhutta ZA: Zinc supplementation for the prevention of pneumonia in children aged 2 months to 59 months. Cochrane Database of Systematic Reviews: Protocols 2006, CD005978.

78. Dyson L, McCormick F, Renfrew MJ: Interventions for promoting the initiation of breastfeeding. Cochrane Database Syst Rev 2005, CD001688.

79. Abdulwadud OA, Snow ME: Interventions in the workplace to support breastfeeding for women in employment. Cochrane Database Syst Rev 2007, CD006177.

80. Wijden Van der C, Kleijnen J, Berk Van den T: Lactational amenorrhea for family planning. Cochrane Database Syst Rev 2003, CD001329.

81. Barlow J, Coren E: Parent-training programmes for improving maternal psychosocial health. Cochrane Database Syst Rev 2004, CD002020.

82. Lerch C, Meissner T: Interventions for the prevention of nutritional rickets in term born children. Cochrane Database Syst Rev 2007, CD006164.

83. Clasen T, Roberts I, Rabie T, Schmidt W, Cairncross S: Interventions to improve water quality for preventing diarrhoea. Cochrane Database Syst Rev 2006, 3:CD004794.

84. Moore ER, Anderson GC, Bergman N: Early skin-to-skin contact for mothers and their healthy newborn infants. Cochrane Database Syst Rev 2007, CD003519.

85. McCall EM, Alderdice FA, Halliday HL, Jenkins JG, Vohra S: Interventions to prevent hypothermia at birth in preterm and/or low birthweight infants. Cochrane Database of Systematic Reviews 2008, CD004210.

86. Conde-Agudelo A, Diaz-Rossello JL, Belizan JM: Kangaroo mother care to reduce morbidity and mortality in low birthweight infants. Cochrane Database Syst Rev 2003, CD002771.

87. Remmington S, Remmington T: Early additional food and fluids for healthy breastfed full-term infants. Cochrane Database of Systematic Reviews: Protocols 2007, CD006462.

88. Sharifah H, Lee KS, Ho JJ: Separate care for new mother and infant versus rooming-in for increasing the duration of breastfeeding. Cochrane Database of Systematic Reviews: Protocols 2007, CD006641.

89. Oladapo OT, Fawole B: Treatments for suppression of lactation. Cochrane Database of Systematic Reviews: Protocols 2006, CD005937.

90. Hofmeyr GJ: Abdominal decompression for suspected fetal compromise/ pre-eclampsia. Cochrane Database Syst Rev 2000, CD000004

91. Prendiville WJ, Elbourne D, McDonald S: Active versus expectant management in the third stage of labour. Cochrane Database Syst Rev 2000, CD000007.

92. Duley L, Henderson-Smart D, Meher S: Altered dietary salt for preventing pre-eclampsia, and its complications. Cochrane Database Syst Rev 2005, CD005548.

93. Roberts D, Dalziel S: Antenatal corticosteroids for accelerating fetal lung maturation for women at risk of preterm birth. Cochrane Database Syst Rev 2006, 3:CD004454.

94. French $L M$, Smaill FM: Antibiotic regimens for endometritis after delivery. Cochrane Database Syst Rev 2004, CD001067.

95. Hopkins L, Smaill F: Antibiotic regimens for management of intraamniotic infection. Cochrane Database Syst Rev 2002, CD003254.

96. Brocklehurst P: Antibiotics for gonorrhoea in pregnancy. Cochrane Database Syst Rev 2002, CD000098.

97. May W, Gulmezoglu AM, Ba-Thike K: Antibiotics for incomplete abortion. Cochrane Database Syst Rev 2007, CD001779.

98. Flenady $\mathrm{V}$, King J: Antibiotics for prelabour rupture of membranes at or near term. Cochrane Database Syst Rev 2002, CD001807.

99. Walker GJ: Antibiotics for syphilis diagnosed during pregnancy. Cochrane Database Syst Rev 2001, CD001143.

100. McDonald HM, Brocklehurst P, Gordon A: Antibiotics for treating bacterial vaginosis in pregnancy. Cochrane Database Syst Rev 2007, CD000262.

101. Howard LM, Hoffbrand S, Henshaw C, Boath L, Bradley E: Antidepressant prevention of postnatal depression. Cochrane Database Syst Rev 2005 , CD004363.

102. Abalos E, Duley L, Steyn DW, Henderson-Smart DJ: Antihypertensive drug therapy for mild to moderate hypertension during pregnancy. Cochrane Database Syst Rev 2007, CD002252.

103. Rumbold A, Duley L, Crowther CA, Haslam RR: Antioxidants for preventing pre-eclampsia. Cochrane Database Syst Rev 2008, CD004227.

104. Duley L, Henderson-Smart DJ, Meher S, King JF: Antiplatelet agents for preventing pre-eclampsia and its complications. Cochrane Database Syst Rev 2007, CD004659.
105. Meremikwu M, Logan K, Garner P: Antipyretic measures for treating fever in malaria. Cochrane Database Syst Rev 2000, CD002151.

106. Gulmezoglu AM, Hofmeyr GJ: Bed rest in hospital for suspected impaired fetal growth. Cochrane Database Syst Rev 2000, CD000034.

107. Sosa C, Althabe F, Belizan J, Bergel E: Bed rest in singleton pregnancies for preventing preterm birth. Cochrane Database Syst Rev 2004, CD003581.

108. Anotayanonth S, Subhedar NV, Garner P, Neilson JP, Harigopal S: Betamimetics for inhibiting preterm labour. Cochrane Database Syst Rev 2004, CD004352.

109. Gulmezoglu AM, Hofmeyr GJ: Betamimetics for suspected impaired fetal growth. Cochrane Database Syst Rev 2001, CD000036.

110. King JF, Flenady VJ, Papatsonis DN, Dekker GA, Carbonne B: Calcium channel blockers for inhibiting preterm labour. Cochrane Database Syst Rev 2003, CD002255.

111. Gulmezoglu AM, Hofmeyr GJ: Calcium channel blockers for potential impaired fetal growth. Cochrane Database Syst Rev 2000, CD000049.

112. Hofmeyr GJ, Atallah AN, Duley L: Calcium supplementation during pregnancy for preventing hypertensive disorders and related problems. Cochrane Database Syst Rev 2006, 3:CD001059.

113. Coyle ME, Smith CA, Peat B: Cephalic version by moxibustion for breech presentation. Cochrane Database Syst Rev 2005, CD003928.

114. Hofmeyr GJ, Kulier R: Cephalic version by postural management for breech presentation. Cochrane Database Syst Rev 2000, CD000051.

115. Drakeley AJ, Roberts D, Alfirevic Z: Cervical stitch (cerclage) for preventing pregnancy loss in women. Cochrane Database Syst Rev 2003, CD003253.

116. Zhang J, Wu TX, Liu GJ: Chinese herbal medicine for the treatment of pre-eclampsia. Cochrane Database Syst Rev 2006, CD005126.

117. Adab N, Tudur SC, Vinten J, Williamson P, Winterbottom J: Common antiepileptic drugs in pregnancy in women with epilepsy. Cochrane Database Syst Rev 2004, CD004848.

118. Hodnett ED, Gates S, Hofmeyr GJ, Sakala C: Continuous support for women during childbirth. Cochrane Database Syst Rev 2007, CD003766.

119. Matchaba P, Moodley J: Corticosteroids for HELLP syndrome in pregnancy. Cochrane Database Syst Rev 2004, CD002076.

120. Okoromah CN, Lesi FE: Diazepam for treating tetanus. Cochrane Database Syst Rev 2004, CD003954.

121. Churchill D, Beevers GD, Meher S, Rhodes C: Diuretics for preventing preeclampsia. Cochrane Database Syst Rev 2007, CD004451.

122. Garner P, Gulmezoglu AM: Drugs for preventing malaria in pregnant women. Cochrane Database Syst Rev 2006, CD000169.

123. Orton L, Garner P: Drugs for treating uncomplicated malaria in pregnant women. Cochrane Database Syst Rev 2005, CD004912.

124. Duley L, Henderson-Smart DJ, Meher S: Drugs for treatment of very high blood pressure during pregnancy. Cochrane Database Syst Rev 2006, 3 CD001449.

125. Villar J, Lydon-Rochelle MT, Gulmezoglu AM, Roganti A: Duration of treatment for asymptomatic bacteriuria during pregnancy. Cochrane Database Syst Rev 2000, CD000491.

126. Hiller JE, Griffith E: Education for contraceptive use by women after childbirth. Cochrane Database Syst Rev 2002, CD001863.

127. Ziino AJ, Davies MW, Davis PG: Epinephrine for the resuscitation of apparently stillborn or extremely bradycardic newborn infants. Cochrane Database Syst Rev 2003, CD003849.

128. Meher S, Duley L: Exercise or other physical activity for preventing preeclampsia and its complications. Cochrane Database Syst Rev 2006 CD005942.

129. Nanda K, Peloggia A, Grimes D, Lopez L, Nanda G: Expectant care versus surgical treatment for miscarriage. Cochrane Database Syst Rev 2006, CD003518.

130. Hofmeyr GJ, Kulier R: Expedited versus conservative approaches for vaginal delivery in breech presentation. Cochrane Database Syst Rev 2000, CD000082

131. Hofmeyr GJ, Kulier R: External cephalic version for breech presentation at term. Cochrane Database Syst Rev 2000, CD000083.

132. Hutton EK, Hofmeyr GJ: External cephalic version for breech presentation before term. Cochrane Database Syst Rev 2006, CD000084.

133. Mangesi L, Hofmeyr GJ: Fetal movement counting for assessment of fetal wellbeing. Cochrane Database Syst Rev 2007, CD004909.

134. Pena-Marti G, Comunian-Carrasco G: Fundal pressure versus controlled cord traction as part of the active management of the third stage of labour. Cochrane Database Syst Rev 2007, CD005462. 
135. Meher S, Duley L: Garlic for preventing pre-eclampsia and its complications. Cochrane Database Syst Rev 2006, 3:CD006065.

136. Hunter S, Hofmeyr GJ, Kulier R: Hands and knees posture in late pregnancy or labour for fetal malposition (lateral or posterior). Cochrane Database Syst Rev 2007, CD001063.

137. Lee C, Gong Y, Brok J, Boxall EH, Gluud C: Hepatitis B immunisation for newborn infants of hepatitis $B$ surface antigen-positive mothers. Cochrane Database Syst Rev 2006, CD004790.

138. Say L, Gulmezoglu AM, Hofmeyr GJ: Hormones for suspected impaired fetal growth. Cochrane Database Syst Rev 2003, CD000109.

139. Crowther CA: Hospitalisation and bed rest for multiple pregnancy. Cochrane Database Syst Rev 2001, CD000110.

140. Stan C, Boulvain M, Hirsbrunner-Amagbaly P, Pfister R: Hydration for treatment of preterm labour. Cochrane Database Syst Rev 2002, CD003096.

141. Horey D, Weaver J, Russell H: Information for pregnant women about caesarean birth. Cochrane Database Syst Rev 2004, CD003858.

142. Gamble C, Ekwaru JP, ter Kuile FO: Insecticide-treated nets for preventing malaria in pregnancy. Cochrane Database Syst Rev 2006, CD003755.

143. Churchill D, Duley L: Interventionist versus expectant care for severe preeclampsia before term. Cochrane Database Syst Rev 2002, CD003106.

144. Lumley J, Oliver SS, Chamberlain C, Oakley L: Interventions for promoting smoking cessation during pregnancy. Cochrane Database Syst Rev 2004, CD001055

145. Neilson JP: Interventions for suspected placenta praevia. Cochrane Database Syst Rev 2003, CD001998.

146. Brocklehurst $P$, Rooney $G$ : Interventions for treating genital chlamydia trachomatis infection in pregnancy. Cochrane Database Syst Rev 2000, CD000054.

147. Neilson JP: Interventions for treating placental abruption. Cochrane Database Syst Rev 2003, CD003247.

148. Hajenius PJ, Mol F, Mol BW, Bossuyt PM, Ankum WM, Veen van der F: Interventions for tubal ectopic pregnancy. Cochrane Database Syst Rev 2007, CD000324

149. Hofmeyr GJ: Interventions to help external cephalic version for breech presentation at term. Cochrane Database Syst Rev 2004, CD000184.

150. Steyn DW, Steyn P: Low-dose dopamine for women with severe preeclampsia. Cochrane Database Syst Rev 2007, CD003515.

151. Crowther CA, Moore V: Magnesium maintenance therapy for preventing preterm birth after threatened preterm labour. Cochrane Database of Systematic Reviews 1998, CD000940.

152. Duley L, Gulmezoglu AM, Henderson-Smart DJ: Magnesium sulphate and other anticonvulsants for women with pre-eclampsia. Cochrane Database Syst Rev 2003, CD000025.

153. Crowther CA, Hiller JE, Doyle LW: Magnesium sulphate for preventing preterm birth in threatened preterm labour. Cochrane Database Syst Rev 2002, CD001060

154. Duley L, Henderson-Smart D: Magnesium sulphate versus diazepam for eclampsia. Cochrane Database Syst Rev 2003, CD000127.

155. Duley L, Gulmezoglu AM: Magnesium sulphate versus lytic cocktail for eclampsia. Cochrane Database Syst Rev 2001, CD002960.

156. Duley L, Henderson-Smart D: Magnesium sulphate versus phenytoin for eclampsia. Cochrane Database Syst Rev 2003, CD000128.

157. Gaunekar NN, Crowther CA: Maintenance therapy with calcium channel blockers for preventing preterm birth after threatened preterm labour. Cochrane Database Syst Rev 2004, CD004071.

158. Say L, Gulmezoglu AM, Hofmeyr GJ: Maternal nutrient supplementation for suspected impaired fetal growth. Cochrane Database Syst Rev 2003, CD000148.

159. Say L, Gulmezoglu AM, Hofmeyr GJ: Maternal oxygen administration for suspected impaired fetal growth. Cochrane Database Syst Rev 2003, CD000137.

160. Neilson JP, Hickey M, Vazquez J: Medical treatment for early fetal death (less than 24 weeks). Cochrane Database Syst Rev 2006, 3:CD002253.

161. Duckitt K, Thornton S: Nitric oxide donors for the treatment of preterm labour. Cochrane Database Syst Rev 2002, CD002860.

162. Meher S, Duley L: Nitric oxide for preventing pre-eclampsia and its complications. Cochrane Database Syst Rev 2007, CD006490.

163. Dodd JM, Crowther CA, Dare MR, Middleton P: Oral betamimetics for maintenance therapy after threatened preterm labour. Cochrane Database of Systematic Reviews 2006, CD003927.
164. Papatsonis D, Flenady V, Cole S, Liley H: Oxytocin receptor antagonists for inhibiting preterm labour. Cochrane Database Syst Rev 2005, CD004452.

165. Hofmeyr GJ, Hannah ME: Planned caesarean section for term breech delivery. Cochrane Database Syst Rev 2003, CD000166.

166. Dare MR, Middleton P, Crowther CA, Flenady VJ, Varatharaju B: Planned early birth versus expectant management (waiting) for prelabour rupture of membranes at term (37 weeks or more). Cochrane Database Syst Rev 2006, CD005302

167. Gulmezoglu AM, Hofmeyr GJ: Plasma volume expansion for suspected impaired fetal growth. Cochrane Database Syst Rev 2000, CD000167.

168. Duley L, Williams J, Henderson-Smart DJ: Plasma volume expansion for treatment of women with pre-eclampsia. Cochrane Database Syst Rev 2000, CD001805.

169. Chaithongwongwatthana S, Yamasmit W, Limpongsanurak S, Lumbiganon P, Desimone JA, Baxter J, Tolosa JE: Pneumococcal vaccination during pregnancy for preventing infant infection. Cochrane Database Syst Rev 2006, CD004903.

170. Dodd JM, Flenady V, Cincotta R, Crowther CA: Prenatal administration of progesterone for preventing preterm birth. Cochrane Database Syst Rev 2006, CD004947.

171. Othman M, Neilson JP, Alfirevic Z: Probiotics for preventing preterm labour. Cochrane Database Syst Rev 2007, CD005941.

172. Meher S, Duley L: Progesterone for preventing pre-eclampsia and its complications. Cochrane Database Syst Rev 2006, CD006175.

173. Wahabi HA, Abed Althagafi NF, Elawad M: Progestogen for treating threatened miscarriage. Cochrane Database Syst Rev 2007, CD005943.

174. Thinkhamrop J, Hofmeyr GJ, Adetoro O, Lumbiganon P: Prophylactic antibiotic administration in pregnancy to prevent infectious morbidity and mortality. Cochrane Database Syst Rev 2002, CD002250.

175. King J, Flenady V: Prophylactic antibiotics for inhibiting preterm labour with intact membranes. Cochrane Database Syst Rev 2002, CD000246.

176. Chongsomchai C, Lumbiganon $\mathrm{P}$, Laopaiboon M: Prophylactic antibiotics for manual removal of retained placenta in vaginal birth. Cochrane Database Syst Rev 2006, CD004904.

177. Whitworth M, Quenby S: Prophylactic oral betamimetics for preventing preterm labour in singleton pregnancies. Cochrane Database Syst Rev 2008, CD006395

178. Yamasmit W, Chaithongwongwatthana S, Tolosa JE, Limpongsanurak S, Pereira L, Lumbiganon P: Prophylactic oral betamimetics for reducing preterm birth in women with a twin pregnancy. Cochrane Database Syst Rev 2005, CD004733.

179. Dennis $C L$, Ross LE, Grigoriadis S: Psychosocial and psychological interventions for treating antenatal depression. Cochrane Database Syst Rev 2007, CD006309.

180. Duley L, Henderson-Smart D: Reduced salt intake compared to norma dietary salt, or high intake, in pregnancy. Cochrane Database Syst Rev 2000, CD001687.

181. Meher S, Duley L: Rest during pregnancy for preventing pre-eclampsia and its complications in women with normal blood pressure. Cochrane Database Syst Rev 2006, CD005939.

182. Flenady V, Wilson T: Support for mothers, fathers and families after perinatal death. Cochrane Database Syst Rev 2008, CD000452.

183. Forna F, Gulmezoglu AM: Surgical procedures to evacuate incomplete abortion. Cochrane Database Syst Rev 2001, CD001993.

184. Nanda K, Cook LA, Gallo MF, Grimes DA: Terbutaline pump maintenance therapy after threatened preterm labor for preventing preterm birth. Cochrane Database Syst Rev 2002, CD003933.

185. Mousa HA, Alfirevic Z: Treatment for primary postpartum haemorrhage. Cochrane Database Syst Rev 2007, CD003249.

186. Alexander J, Thomas P, Sanghera J: Treatments for secondary postpartum haemorrhage. Cochrane Database Syst Rev 2002, CD002867.

187. Vazquez JC, Villar J: Treatments for symptomatic urinary tract infections during pregnancy. Cochrane Database Syst Rev 2003, CD002256.

188. Carroli G, Bergel E: Umbilical vein injection for management of retained placenta. Cochrane Database Syst Rev 2001, CD001337.

189. Hofmeyr GJ, Abdel-Aleem H, Abdel-Aleem MA: Uterine massage for preventing postpartum haemorrhage. Cochrane Database Syst Rev 2008, 3: CD006431.

190. Lede R, Duley L: Uterine muscle relaxant drugs for threatened miscarriage. Cochrane Database Syst Rev 2005, CD002857. 
191. Demicheli V, Barale A, Rivetti A: Vaccines for women to prevent neonata tetanus. Cochrane Database Syst Rev 2005, CD002959.

192. Swadpanich U, Lumbiganon P, Prasertcharoensook W, Laopaiboon M: Antenatal lower genital tract infection screening and treatment programs for preventing preterm delivery. Cochrane Database Syst Rev 2008, CD006178.

193. King J, Flenady V, Cole S, Thornton S: Cyclo-oxygenase (COX) inhibitors for treating preterm labour. Cochrane Database Syst Rev 2005, CD001992.

194. McIntyre PG, Tosh K, McGuire W: Caesarean section versus vaginal delivery for preventing mother to infant hepatitis $C$ virus transmission. Cochrane Database Syst Rev 2006, CD005546.

195. Lumbigannon P, Martis R, Laopaiboon M, Festin MR, Ho JJ, Hakimi M: Antenatal breastfeeding education for increasing breastfeeding duration. Cochrane Database of Systematic Reviews: Protocols 2007, CD006425.

196. Yan Z, Gang CP, Cheng L, Wu S, Zhang M, Gan Chang P: Chinese medicinal herbs for vaginal bleeding of medical abortion. Cochrane Database of Systematic Reviews: Protocols 2007, CD006357.

197. Nardin JM, Carroli G, Alfirevic Z: Combination of tocolytic agents for inhibiting preterm labour. Cochrane Database of Systematic Reviews: Protocols 2006, CD006169.

198. Mathanga DP, Chinkhumba J: Intermittent preventive treatment regimens for malaria in HIV-positive pregnant women. Cochrane Database of Systematic Reviews: Protocols 2007, CD006689.

199. Ehiri JE, Meremikwu A, Meremikwu Martin M: Interventions for preventing unintended pregnancies among adolescents. Cochrane Database of Systematic Reviews: Protocols 2005, CD005215.

200. Papatsonis D, Flenady V: Maintenance therapy with oxytocin antagonists for inhibiting preterm birth after threatened preterm labour. Cochrane Database of Systematic Reviews: Protocols 2006, CD005938.

201. Dodd JM, Crowther CA: Misoprostol for induction of labour to terminate pregnancy in the second or third trimester for women with a fetal anomaly or after intrauterine fetal death. Cochrane Database of Systematic Reviews: Protocols 2004, CD004901.

202. Bugg GJ, Siddiqui F, Thornton JG: Oxytocin versus placebo or no treatment for slow progress in the first stage of spontaneous labour. Cochrane Database of Systematic Reviews: Protocols 2008, CD007123.

203. Buchanan Sarah L, Crowther Caroline A, Levett Kate M, Middleton P, Morris J: Planned early birth versus expectant management for women with preterm prelabour rupture of membranes prior to 37 weeks' gestation for improving pregnancy outcome. Cochrane Database of Systematic Reviews: Protocols 2008, CD004735.

204. Di Mario S, Basevi V, Gagliotti C, Spettoli D, Gori G, D’Amico R, Magrini N: Prenatal education for congenital toxoplasmosis. Cochrane Database of Systematic Reviews: Protocols 2006, CD006171.

205. Su LL, Samuel M, Chong YS: Progestational agents for treating threatened or established preterm labour. Cochrane Database of Systematic Reviews: Protocols 2007, CD006770.

206. Alexander S, Boulvain M, Ceysens G, Haelterman E, Zhang WH: Repeat digital cervical assessment in pregnancy for identifying women at risk of preterm labour. Cochrane Database of Systematic Reviews: Protocols 2006, CD005940.

207. Guppy MP, Mickan SM, Del Mar CB: Advising patients to increase fluid intake for treating acute respiratory infections. Cochrane Database Syst Rev 2005, CD004419.

208. Kabra SK, Lodha R, Pandey RM: Antibiotics for community acquired pneumonia in children. Cochrane Database Syst Rev 2006, 3:CD004874.

209. Bateganya MH, Abdulwadud OA, Kiene SM: Home-based HIV voluntary counseling and testing in developing countries. Cochrane Database Syst Rev 2007, CD006493.

210. Lengeler $C$ : Insecticide-treated bed nets and curtains for preventing malaria. Cochrane Database Syst Rev 2004, CD000363.

211. Jefferson T, Foxlee R, Del Mar C, Dooley L, Ferroni E, Hewak B, Prabhala A, Nair S, Rivetti A: Interventions for the interruption or reduction of the spread of respiratory viruses. Cochrane Database Syst Rev 2007, CD006207.

212. Lewin SA, Dick J, Pond P, Zwarenstein M, Aja G, van Wyk B, BoschCapblanch X, Patrick M: Lay health workers in primary and community health care. Cochrane Database Syst Rev 2005, CD004015.

213. Vidanapathirana J, Abramson MJ, Forbes A, Fairley C: Mass media interventions for promoting HIV testing. Cochrane Database Syst Rev 2005, CD004775.
214. Johnson WD, Diaz RM, Flanders WD, Goodman M, Hill AN, Holtgrave D, Malow R, McClellan WM: Behavioral interventions to reduce risk for sexual transmission of HIV among men who have sex with men. Cochrane Database Syst Rev 2008, CD001230.

215. Rojas MX, Granados C: Oral antibiotics versus parenteral antibiotics for severe pneumonia in children. Cochrane Database Syst Rev 2006, CD004979.

216. Hartling L, Bellemare S, Wiebe N, Russell K, Klassen TP, Craig W: Oral versus intravenous rehydration for treating dehydration due to gastroenteritis in children. Cochrane Database Syst Rev 2006, 3:CD004390.

217. Vidal-Alaball J, Butler CC, Cannings-John R, Goringe A, Hood K, McCaddon A, McDowell I, Papaioannou A: Oral vitamin B12 versus intramuscular vitamin B12 for vitamin B12 deficiency. Cochrane Database Syst Rev 2005, CD004655.

218. Lazzerini M, Ronfani L: Oral zinc for treating diarrhoea in children. Cochrane Database Syst Rev 2008, CD005436.

219. Villar J, Carroli G, Khan-Neelofur D, Piaggio G, Gulmezoglu M: Patterns of routine antenatal care for low-risk pregnancy. Cochrane Database Syst Rev 2001, CD000934.

220. Meremikwu M, Oyo-Ita A: Physical methods for treating fever in children. Cochrane Database Syst Rev 2003, CD004264

221. Marine A, Ruotsalainen J, Serra C, Verbeek J: Preventing occupational stress in healthcare workers. Cochrane Database Syst Rev 2006, CD002892.

222. Rose S, Bisson J, Churchill R, Wessely S: Psychological debriefing for preventing post traumatic stress disorder (PTSD). Cochrane Database Syst Rev 2002, CD000560.

223. Bisson J, Andrew M: Psychological treatment of post-traumatic stress disorder (PTSD). Cochrane Database Syst Rev 2007, CD003388.

224. Thaver D, Saeed MA, Bhutta ZA: Pyridoxine (vitamin B6) supplementation in pregnancy. Cochrane Database Syst Rev 2006, CD000179.

225. Hahn S, Kim S, Garner P: Reduced osmolarity oral rehydration solution for treating dehydration caused by acute diarrhoea in children. Cochrane Database Syst Rev 2002, CD002847.

226. Haider BA, Saeed MA, Bhutta ZA: Short-course versus long-course antibiotic therapy for non-severe community-acquired pneumonia in children aged 2 months to 59 months. Cochrane Database Syst Rev 2008, CD005976.

227. Gruen RL, Weeramanthri TS, Knight SE, Bailie RS: Specialist outreach clinics in primary care and rural hospital settings. Cochrane Database Syst Rev 2004, CD003798.

228. Ni J, Wei J, Wu T: Vitamin A for non-measles pneumonia in children. Cochrane Database Syst Rev 2005, CD003700.

229. Huiming Y, Chaomin W, Meng M: Vitamin A for treating measles in children. Cochrane Database Syst Rev 2005, CD001479.

230. Hemila $H$, Louhiala P: Vitamin C for preventing and treating pneumonia. Cochrane Database Syst Rev 2007, CD005532.

231. Hemila H, Koivula TT: Vitamin $\mathrm{C}$ for preventing and treating tetanus. Cochrane Database Syst Rev 2008, CD006665.

232. Ramsay J, Feder G, Rivas C, Carter YH, Davidson LL, Hegarty K, Taft A, Warburton A: Advocacy interventions to reduce or eliminate violence and promote the physical and psychosocial well-being of women who experience intimate partner abuse. Cochrane Database of Systematic Reviews: Protocols 2005, CD005043.

233. Christopher P, David KV, John SM, Sankarapandian V: Antibiotic therapy for Shigella dysentery. Cochrane Database of Systematic Reviews: Protocols 2007, CD006784.

234. Martín NV, Almeda J, Casabona J: Effectiveness and safety of HIV postexposure prophylaxis after sexual, injecting-drug-use or other nonoccupational exposure. Cochrane Database of Systematic Reviews: Protocols 2005, CD005273.

235. Tanser FC, Pluess B, Lengeler C, Sharp BL: Indoor residual spraying for preventing malaria. Cochrane Database of Systematic Reviews: Protocols 2007, CD006657.

236. Sorsdahl K, Ipser J, Stein DJ: Interventions for Educating Traditional Healers about STD and HIV Medicine. Cochrane Database of Systematic Reviews: Protocols 2008, CD007190.

237. King E, De Silva M, Patel V, Stein A: Interventions for improving the psychosocial wellbeing of children affected by HIV/AIDS. Cochrane Database of Systematic Reviews: Protocols 2007, CD006733.

238. Clasen TF, Bostoen $K$, Schmidt WP, Boisson S, Fung ICH, Jenkins MW, Scott B, Sugden S, Cairncross S: Interventions to improve excreta disposal 
for preventing diarrhoea. Cochrane Database of Systematic Reviews. Protocols 2008, CD007180.

239. Roberts NP, Kitchiner NJ, Kenardy J, Bisson Jl: Multiple session early psychological intervention to prevent and treat post-traumatic stress disorder. Cochrane Database of Systematic Reviews: Protocols 2008, CD006869.

240. Gagnon AJ, Barkun L: Postnatal parental education for improving family health. Cochrane Database of Systematic Reviews: Protocols 2003, CD004068.

241. Gillies D, O'Brien L, Rogers P, Meekings C: Psychological therapies for the prevention and treatment of post-traumatic stress disorder in children and adolescents. Cochrane Database of Systematic Reviews: Protocols 2007, CD006726.

242. Madhivanan P, Tholandi M, Nagamine M: Rapid Tests vs. Traditional Tests for Screening of HIV infections. Cochrane Database of Systematic Reviews: Protocols 2005, CD005174.

243. Taft AJ, Hegarty K, Ramsay J, Feder G, Carter YH, Davidson LL, Warburton A: Screening women for intimate partner violence in health care settings. Cochrane Database of Systematic Reviews: Protocols 2008, CD007007.

244. Lawrence S, De Silva M, Henley R: Sports, games and play-based interventions for post-traumatic stress disorder (PTSD). Cochrane Database of Systematic Reviews: Protocols 2008, CD007171.

245. Appleton R, Macleod S, Martland T: Drug management for acute tonicclonic convulsions including convulsive status epilepticus in children. Cochrane Database Syst Rev 2008, CD001905.

246. Cates CJ, Crilly JA, Rowe BH: Holding chambers (spacers) versus nebulisers for beta-agonist treatment of acute asthma. Cochrane Database Syst Rev 2006, CD000052.

247. Gadomski AM, Bhasale AL: Bronchodilators for bronchiolitis. Cochrane Database Syst Rev 2006, 3:CD001266.

248. Russell K, Wiebe N, Saenz A, Ausejo SM, Johnson D, Hartling L, Klassen TP: Glucocorticoids for croup. Cochrane Database Syst Rev 2004, CD001955.

249. Maconochie I, Baumer H, Stewart ME: Fluid therapy for acute bacterial meningitis. Cochrane Database Syst Rev 2008, CD004786.

250. Glasziou PP, Del Mar CB, Sanders SL, Hayem M: Antibiotics for acute otitis media in children. Cochrane Database Syst Rev 2004, CD000219.

251. Kozyrskyj AL, Hildes-Ripstein GE, Longstaffe SE, Wincott JL, Sitar DS, Klassen TP, Moffatt ME: Short course antibiotics for acute otitis media. Cochrane Database Syst Rev 2000, CD001095.

252. Meremikwu M, Smith HJ: Blood transfusion for treating malarial anaemia. Cochrane Database Syst Rev 2000, CD001475.

253. Puckett RM, Offringa M: Prophylactic vitamin K for vitamin K deficiency bleeding in neonates. Cochrane Database Syst Rev 2000, CD002776.

254. Buckley NA, Eddleston M, Szinicz L: Oximes for acute organophosphate pesticide poisoning. Cochrane Database Syst Rev 2005, CD005085.

255. Roberts D, Buckley NA: Alkalinisation for organophosphorus pesticide poisoning. Cochrane Database Syst Rev 2005, CD004897.

256. Brok J, Buckley N, Gluud C: Interventions for paracetamol (acetaminophen) overdose. Cochrane Database Syst Rev 2006, CD003328.

257. Zupan J, Garner P, Omari AA: Topical umbilical cord care at birth. Cochrane Database Syst Rev 2004, CD001057.

258. Wasiak J, Cleland H, Campbell F: Dressings for superficial and partial thickness burns. Cochrane Database of Systematic Reviews: Protocols 2008, CD002106.

\section{Pre-publication history}

The pre-publication history for this paper can be accessed here: http://www. biomedcentral.com/1471-2458/10/170/prepub

doi:10.1186/1471-2458-10-170

Cite this article as: Turner et al:: Evidence for perinatal and child health care guidelines in crisis settings: can Cochrane help?. BMC Public Health 2010 10:170.

\section{Submit your next manuscript to BioMed Central and take full advantage of:}

- Convenient online submission

- Thorough peer review

- No space constraints or color figure charges

- Immediate publication on acceptance

- Inclusion in PubMed, CAS, Scopus and Google Scholar

- Research which is freely available for redistribution

Submit your manuscript at www.biomedcentral.com/submit
Biomed Central 